\title{
Plyometric training effects on explosive power, sprint and direction change speed in basketball: A review
}

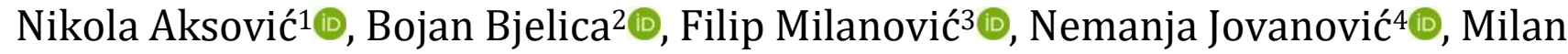 \\ Zelenović2 (10)
}

${ }^{1}$ Faculty of Sport and Physical Education, University of Niš, Serbia. ${ }^{2}$ Faculty of Physical Education and Sport, University of East Sarajevo, Bosnia and Herzegovina. ${ }^{3}$ University Children's Hospital, Belgrade, Serbia. ${ }^{4}$ Faculty of Medicine, University of Priština, Kosovska Mitrovica, Serbia.

\begin{abstract}
Plyometric training involves the use of exercises in which the actual muscles after eccentric contraction become concentric. The aim of this narrative review was to determine the significance and role of plyometric training in basketball, ie this review aimed to determine the influence of plyometric training on the explosive power, sprint, and the change of direction speed of basketball players. The results of this review indicate that plyometric training is an effective method that has a positive effect on short-term maximum performance in basketball. However, some studies have indicated that the effect may be absent on sprint and change of direction speed in basketball players. The general factors of application of plyometric training are age, warm-up, exercises, performance technique, equipment, and surface. The effects of plyometric training can vary depending on factors such as athlete's level, gender, sports activity, duration, type of plyometric training. Therefore, further original studies are needed, in order to further clarify the effect of plyometric training on short-term maximum performance, especially on sprint and change of direction speed of basketball players.
\end{abstract}

Keywords. Basketball, motor skills, plyometrics, short-term performance.

\section{Introduction}

Basketball is a highly intermittent game that involves repeating transitions between attack and defense and frequent movement changes (McInnes et al., 1995). During a basketball game, periods of high-intensity activity are interrupted by periods of low to moderateintensity activity. These activities differ in terms of movement structure (e.g., running, jumping, sideways movement), intensity, distance, frequency, and duration. During a match, jumps occur approximately every minute (Abdelkrim et al., 2007; Scanlan et al., 2011), which is more than in other team sports. In addition, basketball players go through numerous sprints and high-intensity lateral movements (Abdelkrim et al., 2007; Scanlan et al., 2011) that emphasize the need to perform maximum effort during the game. Recent studies (Abdelkrim et al., 2007; Scanlan et al., 2012) recorded a higher frequency of movement and intensity with higher intermittent demands than was originally recorded during a basketball match (McInnes et al., 1995). Variations between current studies and those conducted before 2000 can be attributed in part to rule changes. These rule changes include shortening the attack time after gaining possession of the ball (from $30 \mathrm{~s}$ to $24 \mathrm{~s}$ ) and reducing the time to transfer the ball to the opponent's half (from $10 \mathrm{~s}$ to $8 \mathrm{~s}$ ). These changes are important to note when gathering evidence from existing research spanning decades.

One of the most popular workouts in the 20th century is plyometric training. Plyometric training involves the use of exercises in which the actual muscles after eccentric contraction turn into

М. Zelenović, e-mail: milanzeleni13@gmail.com

Received: April 04, 2021 - Accepted: June 09, 2021 - Published: June 30, 2021

To Cite: Aksović, N., Bjelica, B., Milanović, F., Jovanović, N., Zelenović, M. (2021). Plyometric training effects on explosive power, sprint and direction change speed in basketball: A review. TurkJ Kinesiol, 7(2), 73-79. DOI: 10.31459/turkjkin.929325 
concentric (eg through jumps), and just such a pattern of muscle contraction is very present in many sports, including basketball. The mentioned type of contraction is called reversible, and it represents the muscle elongation-contraction cycle - stretchshortening cycle, SSC (Zatsiorsky \& Kraemer, 2009). SSC is an integral part of plyometric exercises because it improves the ability of musculoskeletal units to produce maximum force in the shortest period (Komi, 2008). Higher forces are associated with shorter damping from the eccentric to the concentric phase and with higher energy stored in the elastic component of the muscle. Also, it should be emphasized that jumps are typical plyometric exercises that cause stress on musculoskeletal units (Taube et al., 2012).

There are different forms of plyometric exercises and they are used depending on the goal of the program, and they are all composed of natural movements (de Villarreal et al., 2009). The basic means of plyometric training methods are vertical, horizontal, and deep jumps (Branković et al., 2008). A typical plyometric program includes countermovement jump (CMJ), the drop jump (DJ), and squat jump (SJ) which can be combined or used separately. The combination of these jumps gives better results than their separate use (de Villarreal et al., 2009; Zelenović et al., 2020). In the literature, plyometrics is often equated with depth jumps, although plyometric exercises, which are characterized by a rapid transition from eccentric to concentric muscle contraction, are in practice used for the upper part of the body, for throwing movements. In plyometrics, exercises can be formulated to isolate different parts of the body for training (Radcliffe \& Farentinos, 2009).

Plyometric exercises can be performed with or without external load, and both methods have been shown to increase explosive power, sprint abilities, and change of direction speed in basketball players (Arazi \& Asadi, 2011; Aksović, 2019). It is often used in sports such as basketball and volleyball to develop vertical jump height, power and coordination (Jamurtas et al., 2000).

The effects of plyometric training can vary depending on different characteristics. The effect of plyometric training on short-term maximum performance (explosive power, sprint, and change of direction speed) may also depend on the characteristics of the subjects, such as the level of an athlete (Stojanović et al., 2017), gender (de Villarreal et al., 2009), an age (Asadi et al., 2016a), sports activity (de Villarreal et al., 2012). Other factors that also determine the effectiveness of plyometric training are duration, type of plyometric training (types of implemented jumps, jumps combined with load training), intensity, and volume (de Villarreal et al., 2009; Stojanović et al., 2017). Thus, the optimal combination of these factors to maximize short-term maximum performance is still unclear to basketball players.

The aim of this narrative review was to determine the significance and role of plyometric training in basketball. Therefore, this review of the current literature aimed to determine the influence of plyometric training on the explosive power, sprint, and the change of direction speed of basketball players.

\section{Theoretical Consideration of the Problem}

\section{History of Plyometric Training}

This training first appeared in Russian sports literature in 1966 in the work of VM Zaciorski. The success of Russian high jumpers and triple jumpers in the 1960s stimulated interest in the systematic application of plyometrics (Radcliffe \& Farentinos, 2009). The name plyometrics is derived from the Greek word "pleythyein", which means to increase. Đinić et al. (2010)emphasize that the name comes from the Latin words "plio" which means more and "metrios" which means measurement, so the whole expression can be translated as "measurable increase".Some trainers also call this method the "shock training method". Verhošanski (1979), the founder of this method, then referred to as the strike method, came up with numerous results that revolutionized training in the development of explosive power. Keohane (1977) showed that skaters who participated in the jump program not only increased the result in the "jump and reach" test, but also achieved an increase of $5.8 \mathrm{~cm}$ in height achieved during the current skating jumps. Hajnal (1985) conducted research in which he opposed the so-called specific method (application of specific jumps that are often represented in the basketball game) and "classic" percussion method (rebound), and the results in the manifestation of these specific jumps were in favor of the specific method. It should be mentioned that plyometric training is a partial reason for the unusual progress and success of Russian sprinter Valery Borzov, the winner of the gold medal in 
the $100 \mathrm{~m}(10 \mathrm{~s}, 14 \mathrm{~s})$ race at the 1972 Olympic Games. Borzov increased the passing time from $13 \mathrm{~s}$, which he achieved from 14 years to $10 \mathrm{~s}$ in his twentieth year (Dintiman, 2010). Many other terms are associated with the term plyometrics, such as stress training, jump training, and elastic reactivity (Radcliffe \& Farentinos, 2009).

\section{General Factors of Application of Plyometric Training}

Since plyometric training includes exercises of higher intensity and the possibility of injury is increased, its application requires special caution. Performing plyometric exercises is simple, does not require special space, and is not expensive (Radcliffe \& Farentinos, 2009). Accordingly, attention should be paid to several important general factors, namely: age, warm-up, exercises, performance technique, equipment, and surface.

Age: The earliest research has indicated that the maturity of the skeletal-nervous system greatly influences the effects of plyometric training (Bosco \& Komi, 1981). Young athletes who have not yet entered puberty should not perform plyometric exercises, and the reason for that is the continuous growth of the bone and joint system, as well as the cartilage on the epiphyseal bone plates in that period (Radcliffe \& Farentinos, 2009).

Warm-up: In order for the plyometric training to be conducted with quality, it is necessary to perform a quality warm-up. It needs to be heated body segments that will be under the influence of the greatest loads foot, ankle, knee, flexor muscles, extensors, and torso rotators (Branković et al., 2008).

Exercises: The basic means of plyometric training are vertical, horizontal, and deep jumps (Branković et al., 2008). Plyometric exercises can be performed with or without external load, and both methods have been shown to increase power, vertical jump height, and sprint ability (Arazi \& Asadi, 2011).

Execution technique: When performing plyometric exercises, especially of maximum intensity, one should focus on the goal of the exercise and the technique of performing it. Jumps should be performed so that contact with the ground lasts as short as possible. In deep jumps, the heel must never hit the ground, ie the center of gravity of the body must be in balance at the time of landing from the aspect of the supporting surface of the foot (Čoh, 2004).

Equipment: Plyometric training can be performed indoors and outdoors. The equipment should provide safety during training and is therefore made of softer materials and without sharp edges (Stefanović et al.,2010).

Surface: The best surface is nurtured grass, then artificial grass, wrestling mats, as well as a sandy surface. Concrete surfaces, hardwood surfaces are not recommended because they do not have good cushioning properties (Čanaki \& Birkić, 2009). Arazi \& Asadi (2011) recommend that plyometric training be performed in water. Aquatic plyometric training can lead to similar benefits as terrestrial but can reduce the risk of injury (Martel et al., 2005). Water reduces the pressure on the musculoskeletal system because water provides buoyancy that reduces the stress caused by weight on the extremities. Viscosity and resistance to movement within water require additional muscle activation to overcome resistance and produce a similar movement that is easier to produce on land or some other surface (Arazi \& Asadi, 2011). Plyometric training in water can help physicians rehabilitate injured athletes (Miller et al., 2006).

\section{Effects of Plyometric Training on Explosive Power}

Explosive power, sprint, and change of direction speed as some of the determinants of the success of basketball, they are the subject of current research. In a constant effort to find the most adequate ways to develop maximum short-term performance, researchers seek to develop existing and find new training methods, to develop and raise motor skills to the level necessary to achieve maximum sports results, in sports where they play an important role. In the following chapters that follow, the mentioned motor abilities will be explained in more detail.

Explosive power, an ability to generate maximum muscle strength in the shortest possible time (Santos \& Janeira, 2008) is an extremely important motor ability to play basketball (Lehnert et al., 2013; Aksović et al., 2020a; Aksović et al., 2021). Vertical jumps are often used to estimate the explosive power of the lower extremities. Vertical jumps are an important factor in basketball because increasing the reach height of athletes can positively affect the result in sports (Häkkinen, 1993). The American National Basketball 
Association (NBA), their fitness and strength training coaches, use plyometric training intensively to improve the explosive power performance of elite professional basketball players (Simenz et al., 2005). The study shows how important jumps, as representatives of explosive power, are for basketball (Okur et al., 2013). The authors determined that the success in the competition was positively related to the result in the vertical jump. In young basketball players of junior and cadet age, plyometric training is recommended as a primary tool in the training process, to increase vertical jumps (Attene et al., 2015; Poomsalood \& Pakulanon, 2015; Asadi et al., 2016a; Bouteraa et al., 2020). Young basketball players often use deep jumps (Asadi \& Arazi, 2012). Hernández et al. (2018) found in a sample of young basketball players that plyometric training lasting seven weeks has a positive effect on the jump height in young basketball players. Snyder et al. (2018) also indicate that plyometric training has a positive effect on jump height. Similar results were obtained in the studies (Latorre Román et al., 2018; Arede et al., 2018).

\section{Effects of Plyometric Training on Sprint}

Basketball, as a physically active sport, depends on numerous motor skills, including short sprints. Short sprint is the ability to increase the speed of movement in minimal time (Bompa \& Haff, 2009), and in basketball, it is most often determined by sprinting at 5 m, 10 m, and 20 m (Delextat \& Cohen, 2009; Bouteraa et al., 2020).

Plyometric training is widely used to improve generalized short-term maximal performance such as sprinting (Aksović et al., 2020b). As cost-effective easily applicable to adult and young basketball players (Asadi et al., 2016a), it is an effective means of increasing the ability to perform short sprints (Poomsalood \& Pakulanon, 2015; Asadi et al., 2016a). Aksović et al. (2020b) obtained results on a sample of young basketball players showing that plyometric training has a positive effect on the sprint $(5 \mathrm{~m}$ and 20 $\mathrm{m})$, while the effect on the $10 \mathrm{~m}$ sprint was absent. However, some studies indicate that plyometric training has proven to be an effective method for improving jump height, while the influence on short sprints is less clear (Bavli, 2011; Bouteraa et al., 2020). A professional basketball player performs short sprints (1 s -2s) $105 \pm 52$ times on average during a game (Castagna et al., 2009). McInnes et al. (1995) in their study of basketball games of the Australian National League indicate that the longest sprint lasted 5.5s, 5\% of sprints lasted longer than $4 \mathrm{~s}$, and the largest number of sprints (51\%) lasted $1.5 \mathrm{~s}-2 \mathrm{~s}$. The average sprint duration was $1.7 \mathrm{~s}$. Also, the high level of the explosive power of the lower extremities of basketball players is positively related to acceleration (Nikolić, 2016).

\section{Effects of Plyometric Training on Change of Direction Speed}

The terms change of direction speed and agility are used interchangeably in the sports literature (Sekulic et al., 2013; Delextrat et al., 2015) although they are not consistent in recent literature. Today, agility is defined as rapid changes in speed or direction of motion, in response to a stimulus (Sheppard et al., 2006). The change of direction speed represents the ability to perform a movement in which there is no direct reaction to the stimulus, ie it represents the movement where the change of direction is planned in advance (Sheppard \& Young, 2006; Stojanović et al., 2019). While agility movements include movements in response to a stimulus (Sheppard \& Young, 2006) the ability to change direction quickly can positively affect agility performance in a variety of sports (Asadi et al., $2016 \mathrm{~b}$ ) and thus in basketball. Thus, the traditional view of agility has since been renamed as the change of direction speed. Therefore, agility and change of direction speed should be observed independently.

Plyometric training is an effective method that leads to improving the change of direction speed of young basketball players (Asadi et al., 2016a; Hernández et al., 2018; Gonzalo-Skoket al., 2019; Aksović, 2019) and basketball player (McCormick et al., 2016). In a doctoral dissertation, Aksović (2019) obtained results that confirm the positive effects of plyometric training lasting 10 weeks on the change of direction speed in young basketball players. Asadi et al. (2016b) also showed that plyometric training improves the rate of change of direction with effects depending on the applied test. Although jumping is a specific activity in basketball, it is possible that the benefit of such training is absent on the sprint and the change of direction speed (Markovic et al., 2007; Bouteraa et al., 2020). Thus, plyometric training can be recommended as an effective form of physical exercise to improve the change of direction speed of basketball players, and the effects can vary depending on a large number of variables, such as training duration, intensity, rest 
interval, sample characteristics (sex, age, training). These variables should be considered by experts to design optimal plyometric training to improve the change of direction speed for a particular sport.

\section{Conclusion}

The results of this review confirm numerous conclusions that plyometric training is an effective method that positively affects the explosive power, sprint abilities, and change of direction speed of basketball players. However, some studies have indicated that the effect may be absent on the sprint and the change of direction speed. This especially refers to the change of direction speed, because this term has been actively used since 2016 . When planning and programming plyometric training, attention should be paid to general factors: age, warm-up, exercises, performance technique, equipment, and surface. The effects of plyometric training can vary depending on factors such as athlete's level, gender, sports activity, duration, type of plyometric training. Therefore, these variables should be taken into account in order to design optimal plyometric training to improve maximum short-term performance in basketball. Thus, further original studies are needed, to further clarify the effect of plyometric training on short-term maximum performance, especially on the sprint and the change of direction speed of basketball players. Certainly, improving plyometric training with the aim of developing maximum short-term performance and achieving optimal physical shape is more than essential for achieving top sports results in basketball.

\section{References}

Abdelkrim, N. B., El Fazaa, S., \& El Ati, J. (2007). Time-motion analysis and physiological data of elite under-19year-old basketball players during competition. $\mathrm{Br}$ JSports Med, 41(2), 69-75.

Aksović, N. (2019). The effects of plyometric training on explosive power, sprint and change of direction speed of young male basketball players. Doctoral Thesis, University of Niš, Faculty of Sport and Physical Education, Serbia.

Aksović, N., Berić, D., Kocić, M., Jakovljević, S., \& Milanović, F. (2020b). Plyometric training and sprint abilities of young basketball players. FU Phys Ed Sport, 17(2), 539-548.
Aksović, N., Bjelica, B.,Milanović,F., Milanović, Lj., \& Jovanović N. (2021). Development of explosive power in basketball players. TurkJ Kinesiol, 7(1), 44-52.

Aksović, N., Kocić, M., Berić, D., \& Bubanj, S. (2020a). Explosive power in basketball players. FU Phys Ed Sport, 18(1), 119-134.

Arazi, H., \& Asadi, A. (2011). The effect of aquatic and land plyometric training on strength, sprint, and balance in young basketball players. J Hum Sport and Exerc, 6(1), 101-111.

Arede, J., Vaz, R., Franceschi, A., Gonzalo-Skok, O., \& Leite, N. (2018). Effects of a combined strength and conditioning training program on physical abilities in adolescent male basketball players. J Sport MedPhys Fitness, 59(8), 12981305.

Asadi, A., \& Arazi, H. (2012). Effects of high-intensity plyometric training on dynamic balance, agility, vertical jump and sprint performance in young male basketball players. J Sport Health Res, 4(1), 35-44.

Asadi, A., Arazi, H., Young, W. B., \& de Villarreal, E. S. (2016b). The effects of plyometric training on change-of-direction ability: A Meta-Analysis. Int J Sports Phys Perform, 11(5), 563-573.

Asadi, A., Ramírez-Campillo, R., Meylan, C., Yuzo, F., Nakamura, R. C. J., \& Izquierdo, M. (2016a). Effects of volume-based overload plyometric training on maximalintensity exercise adaptations in young basketball players. J Sports Med Phys Fitness, 57(12), 1557-1563.

Attene, G., Iuliano, E., Di, A. C., Calcagno, G., Moalla, W., Aquino, G., \& Padulo, J. (2015). Improving neuromuscular performance in young basketball players: plyometric vs. technique training. J Sports Med Phys Fitness, 55(1-2), 1-8.

Bavli, O. (2011). Comparison the effect of water plyometrics and land plyometrics on body mass index and biomotorical variables of adolescent basketball players. IntJ Sport Exerc Sci, 4(1), 11-14.

Bompa, T., \& Haff, G. (2009). Periodization: Theory and methodology of training. Chamapign Il: Human Kinetics.

Bosko, C., \& Komi, P. V. (1981). Potentiation of the mechanical behaviour of the human skeletal muscle trought prestretching. Acta Phys Scand, 106(1), 467-472.

Bouteraa, I., Negra, Y., Shephard, R. J., \& Chelly, M. S. (2020). Effects of combined balance and plyometric training on athletic performance in female basketball players. $J$ Strength Cond Res, 34(7), 1967-1973.

Branković, N., Stojiljković, S., Milenković, D., \& Stanojević, I. (2008). Characteristics of recovery in physical education. Herald of the Anthropological Society of Serbia, 43, 417422. 
Castagna, C., Chaouachi, A., Rampinini, E., Chamari, K., \& Impellizzeri, F. (2009). Aerobic and explosive power performance of elite Italian regional-level basketball players. J Strength Cond Res, 23(7), 1982-1987.

Čanaki, M., \& Birkić, Ž. (2009). Specifics of plyometric training of tennis players. Croat Sports Med J, 24(1), 4550 .

Čoh, M. (2004). Metodika i dijagnostika razvoja skočnosti u kondicijskoj pripremi sportaša (Methodology and diagnostics of jump development in fitness training of athletes). In the proceedings of the International scientific-Professional Conference Fitness Training of Athletes (pp. 104-118), Zagreb: Faculty of Kinesiology. [In Slovenian]

de Villarreal, E. S. S., Kellis, E., Kraemer, W. J., \& Izquierdo, M. (2009). Determining variables of plyometric training for improving vertical jump height performance: A metaanalysis. J Strength Cond Res, 23(2), 495-506.

de Villarreal, E. S., Requena, B., \& Cronin, J. B. (2012). The effects of plyometric training on sprint performance: A meta-analysis. J Strength Cond Res, 26(2), 575-584.

Delextrat, A., \& Cohen, D. (2009). Strength, power, speed, and agility of women basketball players according to 1981. playing position. J Strength CondRes, 23(7), 1974-

Delextrat, A., Grosgeorge, B., \& Bieuzen, F. (2015). Determinants of performance in a new test of planned agility for young elite basketball players. Int J of Sports Phys Perform, 10(2), 160-165.

Dintiman, Dž. B. (2010). Brzina i ubrzanje (Speed and acceleration). In: B. Forlan (Ed.), Top conditioning training (pp. 169-194). Belgrade: Data Status.

Đinić, I., Mihajlović, I., \& Petrović, M. (2010). Effects of different strength training methods on explosive leg strength. TEME: Journal for Social Sciences, 4, 1261-1275.

Gonzalo-Skok, O., Sánchez-Sabaté, J., Izquierdo-Lupón, L., \&Sáez de Villarreal, E. (2019). Influence of force-vector and force application plyometric training in young elite basketball players. Eur J Sport Sci, 19(3), 305-314.

Hajnal, L. (1985). A contribution to the study of the influence of impact and specific work methods on the improvement of jumping in junior basketball players. Master's thesis, Faculty of Sport and Physical Education, University of Belgrade, Serbia.

Häkkinen, K. (1993). Changes in physical fitness profile in female basketball players during the competitive season including explosive type strength training. J Sport MedPhys Fitness, 33, 19-26.

Hernández, S., Ramirez-Campillo, R., Álvarez, C., SanchezSanchez, J., Moran, J., Pereira, L. A., \& Loturco, I. (2018). Effects of plyometric training on neuromuscular performance in youth basketball players: A pilot study on the influence of drill randomization.J Sports Sci Med, 17(3), 372-378.

Jamurtas, A. Z., Fatouros, I. G., Buckenmeyer, P., Kokkinidis, E., Taxildaris, K., Kambas, A., \& Kyriazis, G. (2000). Effects of plyometric exercise on muscle soreness and plasma creatine kinase levels and its comparison with eccentric and concentric exercise. J Strength Cond Res,14(1), 68-74.

Keohane, A. L. (1977). The effects of a six week depth jumping program on the vertical jumping ability of figure skaters. Doctoral dissertation, University of British Columbia, Canada.

Komi, P. (2008). Strength and power in sport (Vol. 3). New Jersey, USA: John Wiley \& Sons.

Latorre Román, P. Á., Villar Macias, F. J., \& García Pinillos, F. (2018). Effects of a contrast training programme on jumping, sprinting and agility performance of prepubertal basketball players. J Sports Sci, 36(7), 802808.

Lehnert, M., Hůlka, K., Malý, T., Fohler, J., \& Zahálka, F. (2013). The effects of a 6 week plyometric training programme on explosive strength and agility in professional basketball players. Acta Gymnica, 43(4), 7-15.

Markovic, G., Jukic, I., Milanovic, D., \& Metikos, D. (2007). Effects of sprint and plyometric training on muscle function and athletic performance. J Strength Cond Res, 21(2), 543-549.

Martel, G. F., Harmer, M. L., Logan, J. M., \& Parker, C. B. (2005). Aquatic plyometric training increases vertical jump in female volleyball players. Med Sci Sports and Exerc, 37(10), 1814-1819.

McCormick, B. T., Hannon, J. C., Newton, M., Shultz, B., Detling, N., \& Young, W. B. (2016). The effects of frontal-and sagittal-plane plyometrics on change-of-direction speed and power in adolescent female basketball players. Int J Sports Phys Perform, 11(1), 102-107.

McInnes, S. E., Carlson, J. S., Jones, C. J., \& McKenna, M. J. (1995). The physiological load imposed on basketball players during competition. J Sports Sci, 13(5), 387-397.

Miller, M. G., Herniman, J. J., Ricard, M. D., Cheatham, C. C., \& Michael, T. J. (2006). The effects of a 6-week plyometric training program on agility. J Sports Sci Med, 5(3), 459465.

Nikolić D. (2016). Complex training of young basketball players. Doctoral Thesis, Faculty of Sport and Physical Education, University of Niš, Serbia.

Okur, F., Tetik, S., \& Koc, H. (2013). An examination of the relationship between vertical jumping performance with competition performance in basketball players. $J$ Health Sci, 22(2), 111-120. 
Poomsalood, S., \& Pakulanon, S. (2015). Effects of 4-week plyometric training on speed, agility, and leg muscle power in male university basketball players: A pilot study. Kas J Soc Sci, 36, 598-606.

Radcliffe, J. \& Farentinos, R. (2009). Pliometrija(Plyometrics). Zagreb: Gopal. In Croatian

Santos, E. J., \& Janeira, M. A. (2008). Effects of complex training on explosive strength in adolescent male basketball players. J Strength Cond Res, 22(3), 903-909.

Scanlan, A. T., Dascombe, B. J., Reaburn, P., \& Dalbo, V. J. (2012). The physiological and activity demands experienced by Australian female basketball players during competition. J Sci Med Sport, 15(4), 341-347.

Scanlan, A., Dascombe, B., \& Reaburn, P. (2011). A comparison of the activity demands of elite and sub-elite Australian men's basketball competition. J Sports Sci, 29(11), 1153-1160.

Sekulic, D., Spasic, M., Mirkov, D., Cavar, M., \& Sattler, T. (2013). Gender-specific influences of balance, speed, and power on agility performance. J Strength Cond Res, 27(3), 802-811.

Sheppard, J. M., \& Young, W. B. (2006). Agility literature review: Classifications, training and testing.J Sports Sci, 24(9), 919-932.

Simenz, C. J., Dugan, C. A., \& Ebben, W. P. (2005). Strength and conditioning practices of National Basketball Association strength and conditioning coaches.J Strength Cond Res, 19(3), 495-504.

Snyder, B., Munford, S., Connaboy, C., Lamont, H., Davis, S., \& Moir, G. (2018). Assessing plyometric ability during vertical jumps performed by adults and adolescents. Sports, 6(4), 132.
Stefanović, Đ., Jakovljević, S., \& Janković, N. (2010). Tehnologija priprem sportista. Beograd: Univerzitet u Beogradu Fakultet sporta i fizičkog vaspitanja. [In Serbian]

Stojanović, E., Aksović, N., Stojiljković, N., Stanković, R., Scanlan, A. T., \& Milanović, Z. (2019). Reliability, usefulness, and factorial validity of change-of-direction speed tests in adolescent basketball players. J Strength Cond Res, 33(11), 3162-3173.

Stojanović, E., Ristić, V., McMaster, D. T., \& Milanović, Z. (2017). Effect of plyometric training on vertical jump performance in female athletes: A systematic review and meta-analysis. Sports Med, 47(5), 975-986.

Taube, W., Leukel, C., \& Gollhofer, A. (2012). How neurons make us jump: the neural control of stretch-shortening cycle movements. Exerc Sport Sci Rev, 40(2), 106-115.

Verhošanski, J. I. (1979). Razvoj snage u sportu (Strength development in sport). Belgrade: Partizan - newspaper publishing and propaganda work organization of the Association for Physical Culture of Yugoslavia. [In Serbian]

Zatsiorsky, V., \& Kraemer, W. (2009). Nauka i praksa u treningu snage (Science and practice in strength training). Beograd: Data Status.

Zelenović, M., Bjelica, B., Lučić, S., \& Djordjević, D. (2020). The impact of plyometric training on explosive strenght in sports. In Proceedings book of the seventh international scientific conference - Anthropological and teoanthropological views on physical activity from the time of Constantine the Great to modern times, (pp. 24-32). Kopaonik: The Faculty of Sport and Physical Education in Leposavić, University of Priština-Kosovska Mitrovica. 